\title{
The impact of delayed critical care outreach team activation on in- hospital mortality and other patient outcomes: a historical cohort study
}

\section{Impact du retard d'activation des équipes d'intervention en soins critiques auprès des patients sur la mortalité à l'hôpital et sur les autres critères d'évaluation des patients : une étude de cohorte historique}

\author{
Bourke W. Tillmann, MD • Michelle L. Klingel, MSc $\cdot$ Shelley L. McLeod, PhD(c), MSc • \\ Scott Anderson, MD · Wael Haddara, MD · Neil G. Parry, MD
}

Received: 8 February 2018/Revised: 15 April 2018/Accepted: 25 April 2018/Published online: 6 July 2018

(C) Canadian Anesthesiologists' Society 2018

\begin{abstract}
Purpose Early warning scores (EWS) and critical care outreach teams (CCOT) have been developed to respond to decompensating patients. Nevertheless, controversy exists around their effectiveness. The primary objective of this study was to determine if a delay of $\geq 60$ min between when a patient was identified as meeting EWS criteria and the CCOT was activated impacted in-hospital mortality.
\end{abstract}

Electronic supplementary material The online version of this article (https://doi.org/10.1007/s12630-018-1180-5) contains supplementary material, which is available to authorized users.

B. W. Tillmann, MD

Department of Critical Care Medicine, Sunnybrook Health

Sciences Centre, Toronto, ON, Canada

B. W. Tillmann, MD (ه)

Sunnybrook Health Sciences Centre, 2075 Bayview Avenue -

Room D108, Toronto, ON M4N 3M5, Canada

e-mail: Bourke.tillmann@sunnybrook.ca

M. L. Klingel, MSc

Translational Medicine, The Hospital for Sick Children,

Toronto, ON, Canada

S. L. McLeod, $\mathrm{PhD}(\mathrm{c}), \mathrm{MSc}$

Department of Family and Community Medicine, Schwartz/

Reisman Emergency Medicine Institute, University of Toronto,

Toronto, ON, Canada

S. Anderson, MD

Division of Emergency Medicine, Department of Medicine,

Schulich School of Medicine and Dentistry, Western University,

London, ON, Canada
Methods This was a historical cohort study evaluating all new CCOT activations over a four-year study period (1 June 2007 to 31 August 2011) for inpatients $\geq 18$ yr of age at two academic tertiary care hospitals in London, Ontario, Canada. Multivariable logistic regression accounting for repeated measures was used to determine the effect of delayed CCOT activation on in-hospital mortality (primary outcome). Differences in outcomes between medical and surgical patients were also examined.

Results There were 3,133 CCOT activations for 1,684 (53.8\%) medical patients and 1,449 (46.2\%) surgical patients during the study period. The CCOT was activated

S. Anderson, MD · N. G. Parry, MD

Trauma Program, London Health Sciences Centre, Victoria Hospital, Western University, London, ON, Canada

S. Anderson, MD · W. Haddara, MD · N. G. Parry, MD Division of Critical Care Medicine, Department of Medicine, Schulich School of Medicine and Dentistry, Western University, London, ON, Canada

W. Haddara, MD

Division of Endocrinology \& Metabolism, Department of Medicine, Schulich School of Medicine and Dentistry, Western University, London, ON, Canada

N. G. Parry, MD

Division of General Surgery, Department of Surgery, Schulich School of Medicine and Dentistry, Western University, London, ON, Canada 
$<60 \mathrm{~min}$ of a patient meeting EWS criteria in 2,160 $(68.9 \%)$ cases and $\geq 60$ min in $973(31.1 \%)$ cases. Patients with $\geq 60$ min delay were more likely be admitted to the intensive care unit (odds ratio [OR], 1.22; 95\% confidence interval [CI], 1.07 to 1.47) and to suffer in-hospital mortality (OR, 1.30; 95\% CI, 1.08 to 1.56). Irrespective of delay, surgical patients were less likely to experience inhospital mortality than medical patients (OR, 0.46; 95\% CI, 0.39 to 0.55 ).

Conclusion Including the rates of delay in CCOT activation and the admitting service could be an additional step in exploring the conflicting results seen in the current literature assessing the impact of CCOT on patient outcomes.

\section{Résumé}

Objet Des scores d'alerte précoce (SAP) et des équipes d'intervention rapide (ou EUM - équipes d'urgence médicale) ont été mis en place pour répondre aux besoins de patients présentant une décompensation de leur état de santé. Leur efficacité est néanmoins controversée. L'objectif principal de cette étude était de déterminer si un délai $\geq 60$ min entre le moment où un patient est identifié comme répondant aux critères du SAP et l'activation de l'EUM avait des répercussions sur la mortalité à l'hôpital.

Méthodes Il s'est agi d'une étude de cohorte historique évaluant toutes les nouvelles activations de l'EUM sur une période de 4 ans (du $1^{\text {er }}$ juin 2007 au 31 août 2011) pour des patients hospitalisés âgés de 18 ans et plus dans deux hôpitaux universitaires de soins tertiaires, à London (Ontario, Canada). Une analyse de régression logistique multifactorielle pour des mesures répétées a permis de déterminer l'effet du retard d'activation de l'EUM sur la mortalité à l'hôpital (critère d'évaluation principal). Les différences d'évolutions entre les patients médicaux et chirurgicaux ont aussi été examinées.

Résultats Il y a eu 3133 activations des EUM pour 1684 patients médicaux (53,8\%) et 1449 patients chirurgicaux (46,2\%) au cours de la période d'étude. Par rapport à l'atteinte des critères de SAP, l'EUM a été activée en moins de 60 minutes dans 2160 (68,9\%) des cas et en $\geq 60$ minutes dans $973(31,1 \%)$ cas. Les patients pour lesquels le délai était $\geq 60$ minutes ont été plus susceptibles d'être admis en unité de soins critiques (rapport de cotes [OR], 1,22; intervalle de confiance [IC] à $95 \%: 1,07$ à 1,47) et de décéder à l'hôpital (OR, 1,30; IC à $95 \%: 1,08$ à 1,56). Indépendamment du délai, les patients chirurgicaux ont été moins susceptibles de décéder à l'hôpital que les patients médicaux (OR, 0,46; IC à $95 \%: 0,39$ à 0,55).

Conclusion L'inclusion des taux de délai d'activation des EUM et du service d'admission pourrait représenter une étape supplémentaire dans l'exploration des résultats contradictoires relevés dans les publications actuelles sur l'impact des EUM sur l'évolution des patients.

To facilitate the identification of in-hospital patients who are acutely decompensating and may require critical care management, early warning scores (EWS) have been developed. ${ }^{1-3}$ These scores, based on changes in clinical status, including respiratory rate, heart rate, systolic blood pressure, and neurologic status, are designed to trigger the activation of critical care outreach teams (CCOT), who respond and attend to the decompensating patient.

Controversy exists around the effectiveness of the EWS and CCOT system. ${ }^{4}$ Multiple studies, including two randomized trials, have reported success in the ability of EWS to identify patients at risk of catastrophic deterioration and poor outcomes, but failed to show a difference in the need for intensive care unit (ICU) admission, cardiopulmonary arrest, or mortality. ${ }^{5-9}$ Moreover, a recent meta-analysis of the use of modified EWS for patients suffering from sepsis has brought into question the ability of these scores to predict mortality. ${ }^{10}$ Conversely, other studies have shown that the implementation of EWS and CCOT has been associated with a decrease in in-hospital cardiac arrests, a reduction in the number of patients receiving cardiopulmonary resuscitation prior to ICU admission, and an improvement in survival to hospital discharge. ${ }^{11-16}$

One possible explanation for these conflicting results is the way in which EWS are being acted upon. ${ }^{1,8}$ Data suggest that EWS are often used to quantify how sick a patient is rather than as a trigger for CCOT activation. ${ }^{17,18}$ As a result, delays in CCOT activation are common. ${ }^{19}$ Three recent studies have shown that a delay in CCOT activation is associated with worse patient outcomes. ${ }^{19-21}$ Nevertheless, none of these studies contained Canadian patients, limiting their external validity as it relates to the Canadian healthcare system. Furthermore, the impact of admitting service was not accounted for in the analyses. Surgical patients have been shown to have different outcomes after CCOT activation than medical patients, and the interaction between delay in CCOT activation and admitting service is unknown. ${ }^{6,22,23}$

The primary objective of this study was to determine if a $\geq 60$ min delay from the time a patient was identified as meeting EWS criteria until the CCOT was activated impacted in-hospital mortality. The secondary objective was to assess differences in outcomes between medical and surgical patients where CCOT was activated. 


\section{Methods}

Study design and patients

This was a historical cohort study of all CCOT activations for inpatients $\geq 18 \mathrm{yr}$ of age at two academic tertiary care hospitals in London, Ontario, between 1 June 2007 and 31 August 2011. Although the CCOT is intended to be activated for hospital inpatients, it is occasionally activated for outpatients. As outpatients represent a different patient population, CCOT activations for outpatients were excluded from this study. All other CCOT activations were included. The study protocol was approved on 6 February 2013 by the Health Sciences Research Ethics Board at The University of Western Ontario.

The criteria and mechanism for the activation of a CCOT at both sites were identical (Fig. 1). Similar to the MERIT (Medical Emergency Response Intervention and Treatment) study, the CCOT is to be activated if any one of the EWS criteria are met. ${ }^{8}$ During the study period, admitted patients were monitored as per routine hospital policies. At both sites, inpatient vital signs are checked every four to six hours as well as at times of clinical concern. Although EWS criteria are not listed in the

\section{cCOT Calling Criteria}

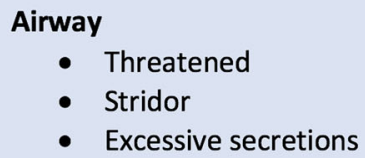

- Stridor

- Excessive secretions

\section{Breathing}

- Respiratory rate $\leq 8$

- Respiratory rate $\geq 30$

- Distressed breathing

- Saturations $<90 \%$ on $\geq 50 \%$ O2 or 6 litres $/ \mathrm{min}$

\section{Circulation}

- Systolic blood pressure $\leq 90 \mathrm{mmHg}$

- Systolic blood pressure $\geq 200 \mathrm{mmHg}$

- A decrease in systolic blood pressure $>40 \mathrm{mmHg}$

- Heart rate $\leq 40$

- Heart rate $\geq 130$

\section{Neurology}

- Decreased level of consciousness

\section{Other}

- Urine output $<100 \mathrm{~mL}$ over $4 \mathrm{hrs}$

- Serious concern about the patient

- Need medical assistance

Fig. 1 Early warning scores and criteria for critical care outreach team (CCOT) activation bedside chart, reminders are placed on all wards and it is expected that if a patient's clinical condition meets EWS criteria, the CCOT is activated. Both of the included sites have a dedicated CCOT available $24 \mathrm{hr}$ a day, seven days a week, comprised of a registered nurse, respiratory therapist, and a critical care physician. To activate the CCOT, a member of the patient's healthcare team calls the CCOT nurse using a dedicated emergency phone number.

Data collection and definitions

Trained members of the CCOT recorded the time the EWS criteria for the CCOT activation were documented in the patient's bedside chart as having been met, the time when the CCOT was called, primary reason for the call, outcome from the patient encounter, patient demographic characteristics, code status, and the patient's primary care team. The type of service under which a patient was admitted was defined by the specialty of the primary care team. Trained research personal extracted the length of ICU and hospital stay, receipt of invasive mechanical ventilation, and in-hospital mortality from the patient's health record and linked this information to the data captured by the CCOT using the patient's unique identification number. All data related to the CCOT activation, including patient characteristics, were entered into the study database the day that the patient was assessed. Outcome data were extracted from the patient record after hospital discharge.

Delay in CCOT activation was defined as the duration of time elapsed between when a patient was identified as having met the EWS criteria and the time CCOT was activated. A clinically significant delay in CCOT activation was defined as a CCOT activation that occurred $\geq 60 \mathrm{~min}$ after the time a patient was documented as having met EWS criteria. This one-hour time frame was chosen based on data from patients with sepsis that showed an increase in mortality for each hour that appropriate antimicrobial therapy was delayed. ${ }^{24}$

\section{Outcomes}

The primary outcome was in-hospital mortality. Secondary patient outcomes included the need for ICU admission, need for invasive mechanical ventilation, ICU length of stay (LOS), and hospital LOS. The effect of delay on the need for ventilation was described two ways: if any ventilation was performed and if patients were ventilated for $>96 \mathrm{hr}$. Extended ventilation represents more complex management, and $96 \mathrm{hr}$ was chosen as this is the current cut-off for extended mechanical ventilation as defined by the International Statistical Classification of Diseases (ICD). 
Statistical analyses

Data were entered directly into a study-specific Microsoft Excel database (Microsoft Corporation, Redmond, WA, USA). Descriptive statistics were summarized using mean (standard deviation [SD]), median [interquartile range (IQR)], or proportional differences where appropriate. Normality was determined by review of kurtosis and skew (acceptable ranges -1 to +1 ), and distribution plots were visually assessed. Proportional differences were assessed using the Pearson Chi-squared statistic. Differences in continuous variables were assessed using an independent $t$ test for normally distributed data, and the Kruskal-Wallis test was used for non-parametric data. The impact of delay in CCOT activation on mortality was analyzed on both a per-activation level and then a perpatient level using the first activation to account for death as a competing variable. Multivariable logistic regression accounting for repeated measures using generalized estimating equations (GEE) was used to determine the effect (odds ratio [OR] with 95\% confidence interval [CI]) of delay in CCOT activation on mortality, ICU admission, and need for ventilation, adjusting for age, sex, hospital site, admitting service, code status, and EWS criteria including the absence of listed criteria. Similar linear regression models were used for hospital and ICU length of stay. All variables included in the models, aside from age, were treated as categorical variables. To evaluate the robustness of the relationship between time to CCOT activation and mortality, two sensitivity analyses were performed on the primary outcome. In the first sensitivity analysis, the multivariable logistic regression using GEE was repeated excluding all patients missing EWS criteria. In the second sensitivity analysis, the multivariable logistic regression using GEE was repeated using time to CCOT activation as a continuous variable.

A pre-specified secondary objective was to determine the impact of admission service on patient outcomes. Similar models were used to determine the effect of admitting service on mortality, adjusting for the delay in CCOT activation. All statistical analyses were done using STATA 12.0 (StataCorp LP, College Station TX, USA).

\section{Results}

Baseline characteristics

There were 3,133 CCOT activations for 1,684 (53.8\%) medical patients and 1,449 (46.2\%) surgical patients during the study period. Of these, 2,160 (68.9\%) activations representing 2,013 unique patients occurred within one hour of the patient meeting EWS criteria, while 973 (31.1\%)

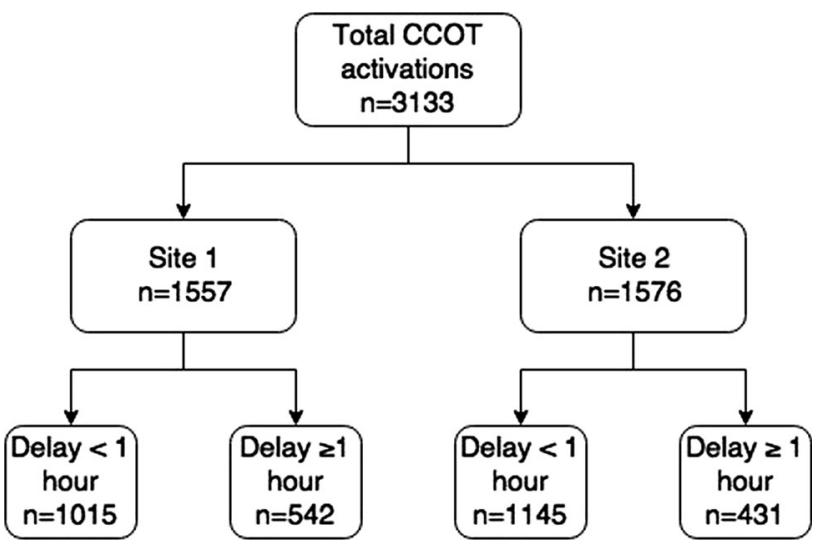

Fig. 2 Flowchart of subjects examined in this study

activations representing 948 unique patients occurred $\geq$ one hour after the patient had met EWS criteria (Fig. 2). Age and sex did not differ significantly between groups, whereas delays of $\geq 60 \mathrm{~min}$ were more common at one of the hospital sites $(P<0.001)$ and among medical admitting services $(P=$ 0.04) (Table 1). Common reasons for CCOT activation were desaturation $(21 \%)$, systolic blood pressure $\leq 90 \mathrm{mmHg}$ (19\%), and altered mental status (12\%). Nevertheless, 1,555 (49.6\%) activations were missing the indication for CCOT activation.

Impact of delay in activation on in-hospital mortality

Outcome data were available for all patients included in the study. In-hospital mortality was significantly higher in the group with a delay in CCOT activation of $\geq 60 \mathrm{~min}$ than in those with CCOT activation $<60 \mathrm{~min}(34.8 \%$ vs $29.4 \%$, respectively; difference, $5.4 \%$; $95 \%$ CI, 1.8 to 9.0 ) (Table 2). To account for the possibility of multiple activations per patient, we limited our analysis to the first CCOT activation. In this analysis, there were 2,853 unique activations with $1,954(68.5 \%)$ occurring within one hour of the patient meeting EWS criteria. In-hospital mortality remained significantly higher in the group with a delay in CCOT activation (34.1\% vs $28.5 \%$; difference, $5.5 \%$; $95 \%$ CI, 1.8 to 9.2). Furthermore, after multivariable regression adjusting for potential confounders deemed clinically relevant, the odds of mortality remained significantly higher among the group with a delay $>60$ min (odds ratio [OR] 1.30; $95 \% \mathrm{CI}, 1.08$ to 1.56 ). Details of the full regression with covariates are shown in the Electronic Supplementary Material (ESM); (ESM Table 1).

The results were also robust after two sensitivity analyses: one in which all patients with a missing cause of CCOT activation were excluded, and another exploratory analysis where time was treated as a continuous value. In the multivariable regression model excluding all patients missing EWS criteria, the 
Table 1 Baseline activation characteristics at the time of CCOT activation compared between delay groups $(n=3,133)$

\begin{tabular}{|c|c|c|c|}
\hline Variable & $\begin{array}{l}\text { Delay }<1 \mathrm{hr} \\
(n=2,160)\end{array}$ & $\begin{array}{l}\text { Delay } \geq 1 \mathrm{hr} \\
(n=973)\end{array}$ & $P$ value \\
\hline Number of patients & 2012 & 948 & \\
\hline Age, mean (SD) & $66.3(16.4)$ & $66.5(16.4)$ & 0.74 \\
\hline \multicolumn{4}{|l|}{ Sex, $n(\%)$} \\
\hline Male & $1161(53.7)$ & $484(49.7)$ & \multirow[t]{3}{*}{0.10} \\
\hline Female & $922(42.7)$ & $455(46.8)$ & \\
\hline Missing & $77(3.6)$ & $34(3.5)$ & \\
\hline \multicolumn{4}{|l|}{ Site, $n(\%)$} \\
\hline 1 & $1015(47.0)$ & $542(55.7)$ & \multirow[t]{2}{*}{$<0.001$} \\
\hline 2 & $1145(53.0)$ & $431(44.3)$ & \\
\hline \multicolumn{4}{|l|}{ Admitting service, $n(\%)$} \\
\hline Medicine & 1135 (52.6) & $549(56.4)$ & \multirow[t]{2}{*}{0.04} \\
\hline Surgery & $1025(47.4)$ & $424(43.6)$ & \\
\hline \multicolumn{4}{|c|}{ Reason for activation, $n(\%) \dagger$} \\
\hline Airway & $34(1.6)$ & $15(1.5)$ & \multirow[t]{7}{*}{$<0.001$} \\
\hline Breathing & $359(16.6)$ & $206(21.2)$ & \\
\hline Circulation & $298(13.8)$ & $171(17.6)$ & \\
\hline Neurology & $359(7.0)$ & $55(5.7)$ & \\
\hline Worried about patient & $102(4.7)$ & $47(4.8)$ & \\
\hline Other & $91(4.2)$ & $48(4.9)$ & \\
\hline Missing & $1124(52.0)$ & $431(44.3)$ & \\
\hline \multicolumn{4}{|c|}{ Code status at time of activation, $N(\%)$} \\
\hline Full & $696(32.2)$ & $386(39.7)$ & \multirow[t]{4}{*}{$<0.001$} \\
\hline No resuscitation & $90(4.2)$ & $38(3.9)$ & \\
\hline Restrictions & $58(2.7)$ & $37(3.8)$ & \\
\hline Missing & $1316(60.9)$ & $512(52.62)$ & \\
\hline
\end{tabular}

CCOT = critical care outreach teams; $\mathrm{HR}=$ heart rate; $\mathrm{SBP}=$ systolic blood pressure; $\mathrm{SD}=$ standard deviation

$\uparrow$ A subset of 1,578 had a primary reason for CCOT activation recorded

relationship between a delay in CCOT activation $\geq 60 \mathrm{~min}$ and in-hospital mortality was further accentuated (OR, 1.37 ; $95 \% \mathrm{CI}, 1.09$ to 1.72 ). For the multivariable regression modeling of the relationship between delayed CCOT activation and in-hospital mortality in which time was treated as a continuous variable, it was necessary to perform a log transformation of time to meet the assumptions of a linear relationship. This model also showed an association between an increase in the duration of the delay in CCOT activation and the odds of in-hospital mortality (OR, 1.07 ; 95\% CI, 1.02 to 1.13 ). Due to the unintuitive nature of log time, we presented our final model with time as a categorical value.

Impact of delay in activation on ICU admission, invasive ventilation, and length of stay

Patients with a delay in CCOT activation $\geq 60$ min were admitted to the ICU more often than those with CCOT activation $<60 \min (47.5 \%$ vs $41.5 \%$; difference, $6.0 \%$; 95\% CI, 2.2 to 9.8). This finding was confirmed by multivariable regression after adjustment for admitting service, site, age, sex, reason for CCOT activation, and code status (OR, 1.22; 95\% CI, 1.07 to 1.47). Nevertheless, no difference was seen in the proportion of patients needing invasive mechanical ventilation after being admitted to the ICU $(62.8 \%$ vs $67.9 \%$; difference, $5.1 \% ; 95 \% \mathrm{CI},-0.3$ to 10.5$)$ or in the proportion of patients requiring prolonged ventilation $(34.2 \%$ vs $32.8 \%$; difference, $1.4 \%$; $95 \% \mathrm{CI},-3.9$ to 6.7$)$. These findings remained constant after multivariable adjustment.

Outcome of patients based on admitting service

Regarding the effect of admitting service, multivariable logistic regression showed that after adjustment for delay, site, age, sex, reason for CCOT activation, and code status, surgical patients were half as likely to suffer in-hospital 
Table 2 Multivariable regression analysis in CCOT activation assessing in-hospital mortality and intensive care utilization among subjects with delays $<$ or $>1 \mathrm{hr}(n=3,133)$

\begin{tabular}{|c|c|c|c|c|}
\hline Outcome & $\begin{array}{l}\text { Delay }<1 \mathrm{hr} \\
(n=2,160)\end{array}$ & $\begin{array}{l}\text { Delay } \geq 1 \mathrm{hr} \\
(n=973)\end{array}$ & $P$ value & Adjusted OR (95\% CI) \\
\hline \multicolumn{5}{|l|}{ In-hospital mortality, } \\
\hline All activations, $n(\%)$ & $636(29.4 \%)$ & $339(34.8 \%)$ & 0.003 & $1.16(0.98$ to 1.36$)$ \\
\hline Restricted to first activation, $n(\%)^{*}$ & $557(28.5 \%)$ & $307(34.1 \%)$ & 0.002 & $1.30(1.08$ to 1.56$)$ \\
\hline Transferred to ICU, $n(\%)$ & $896(41.5 \%)$ & $462(47.5 \%)$ & 0.002 & $1.26(1.07$ to 1.47$)$ \\
\hline Ventilated, $n(\%) \dagger$ & $608(67.9 \%)$ & $290(62.8 \%)$ & 0.06 & $0.88(0.69$ to 1.12$)$ \\
\hline \multirow[t]{2}{*}{ Ventilated $>96 \mathrm{hr}, n(\%) \dagger$} & $294(32.8 \%)$ & $158(34.2 \%)$ & 0.61 & $1.15(0.90$ to 1.46$)$ \\
\hline & & & & Coefficient $(95 \% \mathrm{CI})$ \\
\hline ICU length of stay (hr), median [IQR] & $159[67,349.5]$ & $155[63,328]$ & 0.35 & $-25.8(-81.9$ to 30.4$)$ \\
\hline Hospital length of stay (days), median [IQR] & $16[8,36]$ & $16[8,33]$ & 0.38 & $0.39(-3.4$ to 4.2$)$ \\
\hline
\end{tabular}

*As mortality can occur once per patient but delays can differ between activations, to calculate the in-hospital mortality by delay on a per-patient level, we limited the analysis to the first activation for each patient $(n=1,954$ in delay $<1 \mathrm{hr}$ and $n=899$ in delay $\geq 1 \mathrm{hr})$

$\dagger$ Calculated as the proportion of patients who were transferred to ICU; $n=896$ in delay $<1 \mathrm{hr}$ and $n=462 \mathrm{in}$ delay $\geq 1 \mathrm{hr}$

$\mathrm{CI}=$ confidence interval; CCOT $=$ critical care outreach teams; $\mathrm{ICU}=$ intensive care unit; $\mathrm{IQR}=$ interquartile range; OR = odds ratio

mortality compared with medical patients (OR, 0.46; $95 \%$ CI, 0.39 to 0.55$)$. This was despite the finding that surgical patients were just as likely to be transferred to the ICU as medical patients (OR, $0.93 ; 95 \%$ CI, 0.80 to 1.08$)$ and were more likely to require invasive mechanical ventilation once transferred to the ICU (OR, 1.30; 95\% CI, 1.02 to 1.66) (Table 3).

\section{Discussion}

The implementation of EWS and CCOT was based on the premise that early intervention would mitigate downstream patient harm. Although the data on the impact of EWS and CCOT on patient outcomes are conflicting, multiple studies have shown that EWS and CCOT can decrease in-hospital mortality and evidence is starting to emerge regarding the impact of timely implementation. ${ }^{1-16,19-21}$ Our study is the first Canadian study to examine the relationship between a delay in the activation of CCOT and patient outcomes. Results from our study suggest that for adult patients in which the CCOT is activated, a delay in CCOT activation of $\geq 60$ min after patients have met EWS criteria is associated with a $30 \%$ increase in the odds of morality on a perpatient level and that, regardless of delay, surgical patients for whom the CCOT is activated have a lower mortality than medical patients.

Table 3 Multivariable regression analysis in CCOT activation assessing outcome differences between surgical and medical patients $(n=3,133)$

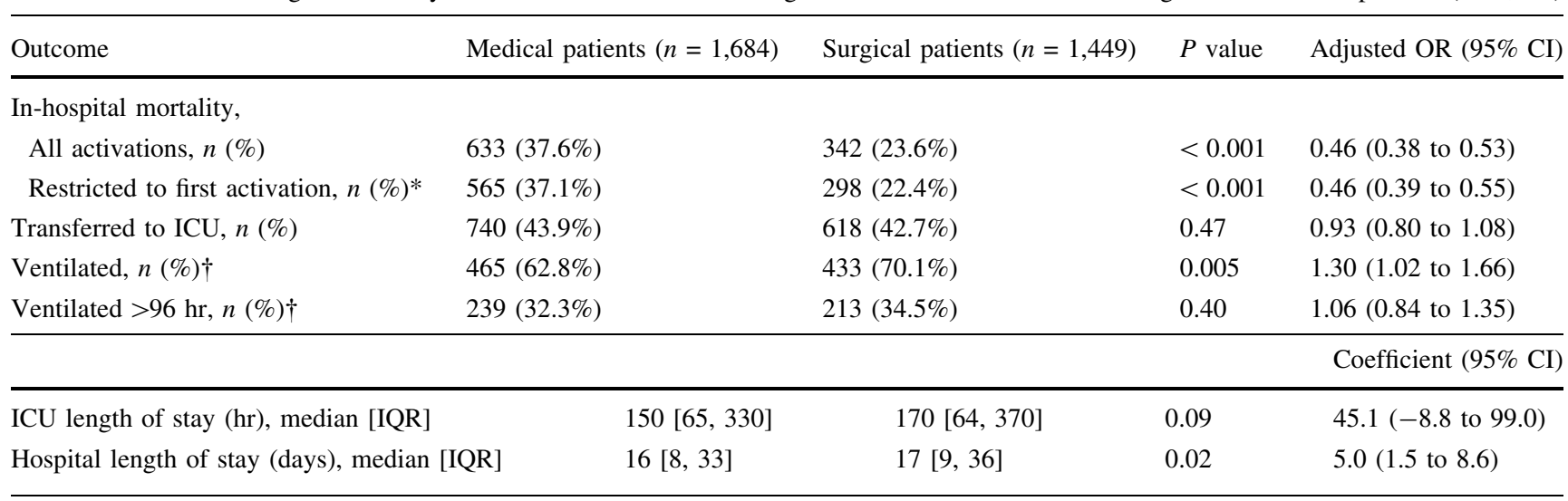

*As mortality can occur once per patient but delays can differ between activations, to calculate the in-hospital mortality by delay on a per-patient level, we limited the analysis to the first activation for each patient $(n=1,522$ in medical patients and $n=1,331$ in surgical patients)

$\dagger$ Calculated as the proportion of patients who were transferred to ICU; $n=740$ in medical and $n=618$ in surgical

$\mathrm{CI}=$ confidence interval $; \mathrm{CCOT}=\mathrm{CCOT}=$ critical care outreach teams; $\mathrm{ICU}=$ intensive care unit $\mathrm{IQR}=$ interquartile range; $\mathrm{OR}=$ odds ratio 
The results of this study are part of a growing pool of data strengthening the hypothesis that a delay in CCOT activation leads to worse patient outcomes. ${ }^{19-21}$ Nevertheless, previous studies have described a significantly higher OR for mortality than found in our study, ranging from 1.6-1.8. ${ }^{19-21}$ This may be due multiple differences between our study and those previously published. For example, the baseline mortality rates in the studies by Boniatti and Chen were significantly higher than the morality observed in our study. ${ }^{20,21}$ Additionally, our study was the only one to include the admission service as a variable in the adjusted model. We showed that surgical patients have lower odds of mortality regardless of their delay, and as the previous studies did not adjust for possible differences in surgical versus medical patients, we were not able to assess their possible influence on patient outcomes. Regardless of these differences, the evidence across all the studies suggests the same: as CCOT activation delays increase, so do the odds of poor patient outcomes.

The impact of a delay in CCOT activation provides a new lens with which to examine the conflicting results of studies looking at the effectiveness of EWS and CCOT. The beneficial impact of CCOT shown in some studies, but not others, may in part be related to differences in adherence to activation criteria. Given that the activation of CCOT was delayed by $>60 \mathrm{~min}$ in nearly a third of the patients in our cohort, it is clear that there is still room for improvement. These results closely mirror those found by Chen et al., which showed that although the implementation of criteria for activating a rapid response team was associated with a decrease in the proportion of delayed activation, delays remained common. ${ }^{20}$

The fact that a larger proportion of patients survived in the surgical group irrespective of length of delay prior to CCOT activation may be related to a number of factors. Patients selected for surgery may be healthier to begin with and, as such, have a higher chance of surviving a clinical deterioration. Additionally, patients in the surgical group may have had readily reversible pathology, and a subsequent surgery or intervention may have been able to address the underlying cause of their deterioration.

This study has multiple strengths. The relatively large sample size allowed for estimation of the effect of the delay in the activation of CCOT on the primary outcome after adjusting for a number of clinical variables. Second, the utilization of two separate hospitals increases the generalizability of the findings. Finally, the long study period helped ensure that the results are not representative of seasonal variability, such as the $2009 \mathrm{H} 1 \mathrm{~N} 1$ pandemic, and mitigated any potential implementation bias.

One limitation of this study is related to the patient cohort. Similar to the other studies that examine delays in
CCOT activation, we only have data for patients where CCOT was activated. As such, it is possible there was a significant number of patients who met the EWS criteria but were never identified or were identified but CCOT was not activated and improved without the involvement of critical care. If this is the case, the $30 \%$ increase in the odds of mortality shown in this study may overestimate the odds of mortality associated with a delay in CCOT activation.

The retrospective nature of this study also presented specific limitations. While the primary outcome (mortality) was not subjective, the two data abstractors were not blinded to the objective of this study. Likewise, we were only able to report what was documented in the patient chart. Although we were able to adjust for age, sex, site, admitting service, reason for CCOT activation, and code status, we were unable to account for the severity of the patient's illness or comorbidities. In addition to the limited number of captured variables, the reason for CCOT activation and the patient's code status were often missing. Nevertheless, when we excluded patients who were missing the reason for CCOT activation from our analysis, we showed an increase in the odds of in-hospital mortality associated with CCOT delay. This suggests that the inclusion of these patients in the analysis biased our results towards the null, further supporting the identified relationship between a delay in CCOT activation and inhospital mortality.

The etiology of the delays in CCOT activation is currently unclear and likely multifactorial. Potential reasons may include a lack of confidence in the EWS/ CCOT system, incomplete dissemination of information regarding CCOT, high workloads limiting the frequency of assessments, and a lack of structured prompts built into the bedside chart. Future initiatives focused on quality improvement should examine the adherence to activation criteria as well as barriers to their utilization in clinical practice. While works such as that done by Dummett et al., ${ }^{25}$ examining the impact of imbedded EWS within the patient chart, and Mohan et al., ${ }^{26}$ assessing methods to improve physician judgement regarding triage decisions, are two such examples, further research is needed.

\section{Conclusions}

A delay in CCOT activation by $>$ one hour was associated with an increase in the odds of in-hospital mortality and ICU admission. Nevertheless, irrespective of delay, surgical patients in which CCOT was activated had reduced in-hospital mortality compared with medical patients. Rates of CCOT delay and details of the admitting service should be included in the interpretation of studies examining the impact of EWS and CCOT 
activation and patient outcomes. Likewise, future endeavours to improve the function of CCOT should include quality improvement initiatives targeted at decreasing delays in activation.

Acknowledgement The authors thank all the members of the CCOT at the London Health Sciences Centre for their role in conducting this study.

Competing interests and funding The authors declare that there are no competing interests.

Editorial responsibility This submission was handled by Dr. Hilary P. Grocott, Editor-in-Chief, Canadian Journal of Anesthesia.

\begin{abstract}
Author contributions Bourke W. Tillmann contributed to the conception and design of the study, assisted with ethics approval, analyzed and interpreted the data, and was the primary author of the manuscript. Michelle L. Klingel contributed to the design of the study, obtained ethics approval, analyzed and interpreted the data, and was involved in drafting the manuscript. Shelley L. McLeod aided in analysis, interpretation of the data, and editing of the manuscript. Scott Anderson contributed to the design and creation of the study. Wael Haddara contributed to the creation and acquisition of the data. Neil G. Parry contributed to the conception and design of the study and was a major contributor to writing the manuscript. All authors approved the final manuscript.
\end{abstract}

Funding No financial support was provided for this project. The study protocol was approved by the Health Sciences Research Ethics Board at The University of Western Ontario, file number 103433.

\section{References}

1. Johnstone CC, Rattray J, Myers L. Physiological risk factors, early warning scoring systems and organizational changes. Nurs Crit Care 2007; 12: 219-24.

2. McArthur-Rouse F. Critical care outreach services and early warning scoring systems: a review of the literature. J Adv Nurs 2001; 36: 696-704.

3. Roney JK, Whitley BE, Maples JC, Futrell LS, Stunkard KA, Long $J D$. Modified early warning scoring (MEWS): evaluating the evidence for tool inclusion of sepsis screening criteria and impact on mortality and failure to rescue. J Clin Nurs 2015; 24: 3343-54.

4. Smith ME, Chiovaro JC, O'Neil M, et al. Early warning system scores for clinical deterioration in hospitalized patients: a systematic review. Ann Am Thorac Soc 2014; 11: 1454-65.

5. Subbe CP, Davies RG, Williams E, Rutherford P, Gemmell L. Effect of introducing the Modified Early Warning score on clinical outcomes, cardio-pulmonary arrests and intensive care utilisation in acute medical admissions. Anaesthesia 2003; 58: 797-802.

6. Patel MS, Jones MA, Jiggins M, Williams SC. Does the use of a "track and trigger" warning system reduce mortality in trauma patients? Injury 2011; 42: 1455-9.

7. Bailey TC, Chen $Y$, Mao $Y$, et al. A trial of a real-time alert for clinical deterioration in patients hospitalized on general medical wards. J Hosp Med 2013; 8: 236-42.

8. Hillman K, Chen J, Cretikos M, et al. Introduction of the medical emergency team (MET) system: a cluster-randomised controlled trial. Lancet 2005; 365: 2091-7.
9. Karpman C, Keegan MT, Jensen JB, Bauer PR, Brown DR, Afessa $B$. The impact of rapid response team on outcome of patients transferred from the ward to the ICU: a single-center study. Crit Care Med 2013; 41: 2284-91.

10. Hamilton F, Arnold D, Baird A, Albur M, Whiting P. Early warning scores do not accurately predict mortality in sepsis: a meta-analysis and systematic review of the literature. J Infect 2018; 76: 241-8.

11. Moon A, Cosgrove JF, Lea D, Fairs A, Cressey DM. An eight year audit before and after the introduction of modified early warning score (MEWS) charts, of patients admitted to a tertiary referral intensive care unit after CPR. Resuscitation 2011; 82: 150-4.

12. Green AL, Williams A. An evaluation of an early warning clinical marker referral tool. Intensive Crit Care Nurs 2006; 22: 274-82.

13. Bristow PJ, Hillman KM, Chey T, et al. Rates of in-hospital arrests, deaths and intensive care admissions: the effect of a medical emergency team. Med J Aust 2000; 173: 236-40.

14. Buist MD, Moore GE, Bernard SA, Waxman BP, Anderson JN, Nguyen TV. Effects of a medical emergency team on reduction of incidence of and mortality from unexpected cardiac arrests in hospital: preliminary study. BMJ 2002; 324: 387-90.

15. Ludikhuize J, Brunsveld-Reinders AH, Dijkgraaf $M G$, et al. Outcomes associated with the nationwide introduction of rapid response systems in the Netherlands. Crit Care Med 2015; 43: 2544-51.

16. Jones D, Egi M, Bellomo R, Goldsmith D. Effect of the medical emergency team on long-term mortality following major surgery. Crit Care 2007; 11: R12.

17. Subbe CP, Williams E, Fligelstone L, Gemmell L. Does earlier detection of critically ill patients on surgical wards lead to better outcomes? Ann R Coll Surg Engl 2005; 87: 226-32.

18. Donohue LA, Endacott $R$. Track, trigger and teamwork: communication of deterioration in acute medical and surgical wards. Intensive Crit Care Nurs 2010; 26: 10-7.

19. Barwise A, Thongprayoon C, Gajic O, Jensen J, Herasevich V, Pickering $B W$. Delayed rapid response team activation is associated with increased hospital mortality, morbidity, and length of stay in a tertiary care institution. Crit Care Med 2016; 44: 54-63.

20. Chen J, Bellomo R, Flabouris A, Hillman $K$, Assareh $H, O u L$. Delayed emergency team calls and associated hospital mortality: a multicenter study. Crit Care Med 2015; 43: 2059-65.

21. Boniatti MM, Azzolini N, Viana MV, et al. Delayed medical emergency team calls and associated outcomes. Crit Care Med 2014; 42: 26-30.

22. Moroseos T, Bidwell K, Rui L, et al. Rapid response team implementation on a burn surgery/acute care ward. J Burn Care Res 2014; 35: 21-7.

23. Jones D, Opdam H, Egi M, et al. Long-term effect of a Medical emergency team on mortality in a teaching hospital. Resuscitation 2007; 74: 235-41.

24. Kumar A, Roberts D, Wood KE, et al. Duration of hypotension before initiation of effective antimicrobial therapy is the critical determinant of survival in human septic shock. Crit Care Med 2006; 34: 1589-96.

25. Dummett BA, Adams C, Scruth E, Liu V, Guo M, Escobar GJ. Incorporating an early detection system into routine clinical practice in two community hospitals. J Hosp Med 2016; 11(Suppl 1): $\mathrm{S} 25-31$

26. Mohan D, Farris C, Fischhoff B, et al. Efficacy of educational video game versus traditional educational apps at improving physician decision making in trauma triage: randomized controlled trial. BMJ 2017; 359: j5416. 